\title{
Disruption of function-structure coupling in brain regions sub-serving self monitoring in schizophrenia
}

\section{Citation}

Araki, Tsuyoshi, Margaret Niznikiewicz, Toshiro Kawashima, Paul G. Nestor, Martha E. Shenton, and Robert W. McCarley. 2013. Disruption of Function-structure Coupling in Brain Regions

Sub-Serving Self Monitoring in Schizophrenia. Schizophrenia Research 146, no. 1-3: 336-343. doi:10.1016/j.schres.2013.02.028.

\section{Published Version}

doi:10.1016/j.schres.2013.02.028

\section{Permanent link}

http://nrs.harvard.edu/urn-3:HUL.InstRepos:28548721

\section{Terms of Use}

This article was downloaded from Harvard University's DASH repository, and is made available under the terms and conditions applicable to Other Posted Material, as set forth at http:// nrs.harvard.edu/urn-3:HUL.InstRepos:dash.current.terms-of-use\#LAA

\section{Share Your Story}

The Harvard community has made this article openly available.

Please share how this access benefits you. Submit a story.

Accessibility 


\section{Disruption of function-structure coupling in brain regions sub- serving self monitoring in schizophrenia}

Tsuyoshi Araki, M.D., Ph.D., Margaret Niznikiewicz, Ph.D., Toshiro Kawashima, M.D., Ph.D., Paul G. Nestor, Ph.D, Martha E. Shenton, Ph.D., and Robert W. McCarley, M.D.

Clinical Neuroscience Division, Laboratory of Neuroscience, Department of Psychiatry (116A), Boston VA Healthcare System, Brockton Division and Harvard Medical School, 940 Belmont St., Brockton, MA 02301

\section{Summary}

Deficits in self monitoring are a core feature of cognitive dysfunction in schizophrenia, and may be the basis for disturbances of self and lack of insight, ultimately impacting social functioning. However, the functional and structural neural correlates of such deficits in self monitoring are not well understood. We investigated this issue using measurements of neurophysiological and structural brain indices, i.e., error-related and correct-response negativity (ERN \& CRN) of eventrelated potentials, and gray matter volume of the anterior cingulate cortex (ACC), and tested whether the association between these indices is altered in patients with schizophrenia. Participants consisted of 18 male patients with chronic schizophrenia and 18 healthy male controls. The 2 groups did not differ in ERN amplitude. In contrast, schizophrenia patients showed significantly larger CRN amplitudes than did healthy subjects. Although the 2 groups did not significantly differ in gray matter volume of the ACC subregions, a significant negative correlation was found between ERN amplitudes at the frontocentral electrodes and absolute gray matter volumes of the left cognitive region of ACC only in healthy controls. These results suggest a disruption of function-structure coupling of the brain regions sub-serving self monitoring in schizophrenia.

\section{Introduction}

Deficiency in self monitoring is a core feature of cognitive dysfunction in schizophrenia, and may be the basis for disturbances of self and lack of insight, ultimately impacting social functioning. An objective biological marker for self monitoring can be elicited by an eventrelated potentials (ERP) component described as error negativity (Ne) (Falkenstein et al., 1991) or error-related negativity (ERN) (Gehring et al., 1993).

\footnotetext{
(C) 2012 Elsevier B.V. All rights reserved.
}

Publisher's Disclaimer: This is a PDF file of an unedited manuscript that has been accepted for publication. As a service to our customers we are providing this early version of the manuscript. The manuscript will undergo copyediting, typesetting, and review of the resulting proof before it is published in its final citable form. Please note that during the production process errors may be discovered which could affect the content, and all legal disclaimers that apply to the journal pertain.

\section{Conflict of Interest}

All authors declared no conflict of interest including any financial, personal or other relationships with other people or organizations within 3 years of beginning the work submitted that could inappropriately influence, or be perceived to influence, their work.

\section{Contributors}

Tsuyoshi Araki designed the study, wrote the protocol, managed the literature searches and analyses, undertook the statistical analysis, and wrote the first draft of the manuscript. Margaret Niznikiewicz and Robert W. McCarley supervised the study and contributed to the study design, data collection, data analysis, and interpretation of data. Toshiro Kawashima, Paul G. Nestor and Martha E. Shenton contributed to data collection, data analysis, and interpretation of data. All authors contributed to and have approved the final manuscript. 
The ERN is theorized to be related to self-monitoring, particularly to aspects of both error detection and response conflict (Falkenstein et al., 1991; Gehring et al., 1993). The ERN can be measured during several different speeded response tasks, including the arrows version of the Erikson Flankers task, Simon task, color Stroop task, and Go/No-Go task (Olvet and Hajcak, 2008). The ERN appears as a negative deflection approximately $50-100 \mathrm{msec}$ following an erroneous response, and is measured at midline frontal and central electrode sites (i.e., Fz and $\mathrm{Cz}$ ). The interpretation of the ERN is based on the hypothesis that the ERN reflects the detection of errors. In recent years, the hypothesis has developed and the ERN is now commonly thought to reflect response conflict rather than simple errors (Botvinick et al., 1999; Botvinick et al., 2001; Botvinick et al., 2004; Carter et al., 1998; van Veen and Carter, 2002; van Veen et al., 2001).

Another ERP component that is potentially related to error processing is the correct response negativity $(\mathrm{CRN})$, which is a response-related, frontocentral negative component appearing following correct trials (Falkenstein et al., 2000; Ford, 1999; Vidal et al., 2000). The CRN has a similar peak latency and topography to the ERN, but it is smaller in amplitude.

Although the CRN might also reflect some aspects of response conflict, the precise nature of the CRN is not fully understood.

Patients with schizophrenia showed diminished error-related negativity (ERN) (Alain et al., 2002; Bates et al., 2002; Bates et al., 2004; Kim et al., 2006; Kopp and Rist, 1999; Mathalon et al., 2002; Morris et al., 2008; Morris et al., 2006), which has been interpreted as indexing self monitoring deficits in schizophrenia. These studies used several different kinds of experimental tasks, including the Erikson flanker task (Kopp and Rist, 1999; Morris et al., 2006), color Stroop task (Alain et al., 2002; Kim et al., 2006), Go/No-go task (Bates et al., 2002; Bates et al., 2004), picture-word naming task (Mathalon et al., 2002), and probabilistic learning task (Morris et al., 2008). This reduced ERN potentially reflects an abnormality in the self-monitoring system in patients with schizophrenia. On the other hand, some studies have shown that patients with schizophrenia exhibit an enhanced CRN compared to healthy controls (Alain et al., 2002; Kim et al., 2006; Mathalon et al., 2002; Morris et al., 2006).

The ERN has been shown to originate in the anterior cingulate cortex (ACC) by using source localization, LORETA source localization, magnetoencephalography, and functional MRI (Herrmann et al., 2004; Holroyd et al., 1998; Kiehl et al., 2000; Miltner et al., 2003; van Veen and Carter, 2002). Lesion studies have also shown that patients with ACC lesions showed diminished ERNs (Stemmer et al., 2004). The ACC is functionally subdivided into caudal cognitive, rostral affective, and subgenual subregions (Bush et al., 2000). The cognitive subregion of ACC contributes to the Stroop task without emotionally biased stimuli (Bush et al., 1999), while the emotional Stroop task specifically activates the rostral, affective subdivision of ACC (Whalen et al., 1998). FMRI studies tend to report rostral ACC activation during error processing (Kiehl et al., 2000; Laurens et al., 2003). However, EEG studies and those combined with fMRI have clarified spatiotemporal characteristics of error processing within the ACC: error monitoring process at an earlier stage is associated with a more caudal region, while the later evaluation process may be associated with a more rostral region (Edwards et al., 2012; Herrmann et al., 2004; van Veen and Carter, 2002). Thus, it may be hypothesized that the ERN detected at $100-150 \mathrm{msec}$ post-stimulus would be localized to the more caudal cognitive subregion. To date, however, no study has investigated the correlation between ERN amplitudes and gray matter volumes of ACC in patients with schizophrenia. One study has investigated the relationship between ERN amplitude and cingulum bundle integrity as indexed by diffusion tensor imaging in healthy subjects, and observed an association with posterior, not anterior part of the left cingulum (Westlye et al., 2009). 
Accordingly, in order to clarify the brain structural basis of self-monitoring related electrophysiological abnormalities in schizophrenia, we measured ERPs by using the color Stroop task and the ACC gray matter volumes obtained from MRI using Region of Interest (ROI) manual tracing. Correlations between the ERN/CRN and gray matter volumes of ACC subregions were examined in both patients with schizophrenia and healthy controls. In light of the inferences from previous EEG/fMRI studies (Edwards et al., 2012; Herrmann et al., 2004; van Veen and Carter, 2002), we predicted an ERN association with the cognitive subregion of the ACC in healthy subjects which would be disrupted in schizophrenia patients.

\section{Methods}

\section{Subjects}

The present study included 18 male patients with chronic schizophrenia and 18 healthy men, all with normal or corrected-to-normal vision, all right handed, and with an age range of 2055 years. After a complete explanation of the study, all participants signed an informed consent form in accordance with Harvard Medical School and VA Boston Healthcare System guidelines. The exclusion criteria were (1) a history of neurological illness or major head trauma that might result in an abnormal EEG, (2) a history of electro convulsive therapy, (3) a history of alcohol or drug dependence, (4) alcohol or drug abuse within the past 5 years, and (5) a verbal IQ below 75 . Healthy controls were recruited through a newspaper advertisement and were screened using the Structured Clinical Interview for DSM-III-R-Non-Patient Edition (SCID-NP). No control subjects had any axis I psychiatric disorder, nor did their first-degree relatives. The patients were recruited from the VA Boston Healthcare System, Brockton Division, and had a diagnosis of schizophrenia on the basis of their medical records and assessment with the patient edition of the SCID for DSM-IV. Mean age in the patient and control groups was 44.0 (SD 10.3) and 36.9 (SD 12.0), respectively. Handedness was assessed using the Edinburgh Inventory, and the socioeconomic status of subjects and their parents was measured by using the Hollingshead two-factor index. The Positive and Negative Syndrome Scale (PANSS) was administered to patients. All subjects underwent ERP recordings. All of the patients and 14 healthy controls underwent MRI recordings. The median interval between these recordings was 11 months. This study was approved by the VA Boston health care system and Harvard Medical School Institutional Review Boards.

\section{ERP recording}

In order to elicit ERN and CRN, we used the Stroop task. Subjects were seated in a comfortable chair, facing a monitor, which was located $1 \mathrm{~m}$ from their eyes. Subjects were instructed to identify the color in which stimuli were printed by pressing 1 of 4 response-pad buttons with the index and middle fingers of both hands. Prior to the Stroop task, learning and practice sessions were conducted. In the learning session, Xs printed in 4 colors (red, green, yellow, \& blue) were presented on the monitor. In the practice session, words (RED, GREEN, YELLOW, and BLUE) and Xs printed in 4 colors were presented and subjects were given feedback as to whether their response was correct. The average response time from the second half of the practice session defined the threshold for the warning sound during the actual testing session. During the actual task, congruent (e.g., RED printed in red color), incongruent (e.g., RED printed in blue color), and neutral (Xs printed in 4 colors) stimuli were presented. One block consisted of 432 stimuli (144 congruent, 144 incongruent, $\& 144$ neutral) and 3 blocks were performed. The importance of speed and accuracy were equally emphasized. Stimuli appeared on the screen for $500 \mathrm{msec}$, followed by a blank screen with a fixation point for $1,500 \mathrm{msec}$. If the subject responded slower than the individually defined threshold time, a warning sound was delivered over the headphones. 
The warning sound was aimed at maintaining subjects' alertness and at increasing the error rate to obtain a sufficient number of error trials for ERP analysis. The entire task required about 45 min to complete. The EEG was recorded $(0.01-100 \mathrm{~Hz}, 500 \mathrm{~Hz}$ digitization) using 64 silver-silver chloride sintered electrodes in preconfigured caps (ElectroCap International, Eaton, Ohio). The electrode sites were as follows: Fp1/Fp2, F7/F8, F5/F6, F3/F4, F1/Fz/F2, FT9/FT10, FT7/FT8, FC5/FC6, FC3/FC4, FC1/FC2, T9/T10, T7/T8, C5/C6, C3/C4, C1/Cz/ C2, TP7/TP8, CP5/CP6, CP3/CP4, CP1/CP2, P9/P10, P7/P8, P5/P6, P3/P4, P1/Pz/P2, PO9/ $\mathrm{PO} 10, \mathrm{PO} 7 / \mathrm{PO} 8, \mathrm{PO} 1 / \mathrm{PO} 2$, and $\mathrm{O} 1 / \mathrm{Oz} / \mathrm{O} 2$, referenced to the right earlobe, with the ground electrode positioned on the forehead. The vertical electrooculogram (EOG) was recorded using 2 electrodes located medially to the right eye, one above and the other below the eye. The horizontal EOG was recorded at the outer canthi. Electrode impedances were $<5 \mathrm{k} \Omega$. In off-line analyses, the event-related potential responses were convolved with a zero phase shift digital low-pass filter at $16 \mathrm{~Hz}$ ( $24 \mathrm{db} /$ octave). Epochs were $800 \mathrm{msec}$ in duration, including a 400-msec pre-response interval. Epochs at each electrode site were baseline corrected by subtraction of the average voltage of a $100-\mathrm{msec}$ period before the response onset, and mathematically corrected for eye movement artifacts. Subsequently, epochs exceeding $\pm 100 \mu \mathrm{V}$ at any electrode site were rejected. Final event-related potential responses were re-referenced off-line to the average of the left and right earlobe potentials. The ERN and CRN were measured as the average amplitude between 25 and $150 \mathrm{msec}$ postresponse. Because the ERN and CRN are typically largest at frontal and central sites, the analyses included the left, midline, and right frontal and central electrodes (i.e. F3, Fz, F4, $\mathrm{C} 3, \mathrm{Cz}, \mathrm{C} 4)$.

\section{MR imaging procedures}

The MRI protocol used 2 pulse sequences on a 1.5-T MRI system (GE Medical Systems, Milwaukee), as described in detail elsewhere (Wible et al., 1995). Briefly, a 3-dimensional Fourier transformed spoiled gradient-recalled (SPGR) acquisition sequence yielded contiguous coronal SPGR images $(\mathrm{TE}=5 \mathrm{~ms}, \mathrm{TR}=35 \mathrm{~ms}$, repetition $=1$, nutation angle $=$ $45^{\circ}$, field of view $=24 \mathrm{~cm}$, acquisition matrix $=256 \times 256 \times 124$, voxel dimension $=0.9375$ $\times 0.9375 \times 1.5 \mathrm{~mm}$ ). Next, a double-echo spin-echo yielded contiguous axial (54 protondensity- and $54 \mathrm{~T} 2$-weighted) slices throughout the brain ( $\mathrm{TE}=30$ and $80 \mathrm{~ms}, \mathrm{TR}=3,000$ $\mathrm{ms}$, field of view $=24 \mathrm{~cm}$, an interleaved acquisition with 3-mm slice thickness, voxel dimensions $=0.9375 \times 0.9375 \times 3.0 \mathrm{~mm}$ ). Images were realigned using the anterior commissure/posterior commissure line and the sagittal sulcus to correct for head tilt, and resampled into isotropic voxels $\left(0.9375 \mathrm{~mm}^{3}\right)$.

All manual processes were performed blind to patient diagnoses. The ROI included the gray matter of cognitive, affective, and subgenual subregions of the anterior cingulate cortex, which were outlined manually on a workstation. We used the same protocol for the manual tracing of ACC as in a previous study (Koo et al., 2008). Briefly, the cingulate gyrus was bounded superiorly by the cingulate sulcus, and inferiorly by the callosal sulcus on each of the coronal slices. The anatomical landmark for dividing the cingulate gyrus into anterior and posterior regions was a vertical line passing through the anterior commissure point in the mid-sagittal slice. Within the anterior cingulate gyrus, further parcellations were made forming subgenual, affective (antero-rostral), and cognitive (antero-caudal) subregion ROIs. The subgenual subregion was defined as the cingulate area underneath the corpus callosum, bounded anteriorly by the line passing through the anterior margin of the genu of the corpus callosum, and posteriorly 1 slice anterior to the internal capsule dividing the striatum. The affective subregion was bounded anteriorly by the cingulate sulcus, and posteriorly above the corpus callosum by the line passing through the most anterior point of the inner surface of the genu of the corpus callosum, and superior to the subgenual region below the corpus 
callosum. The cognitive subregion was defined as the remaining ACC between the affective subregion and posterior cingulate gyrus.

Some, but not all, brains contained a paracingulate sulcus, parallel to the cingulate sulcus. The paracingulate sulcus was judged as present if at least $20 \mathrm{~mm}$ in length on a sagittal view, and if the paracingulate gyrus was clearly independent from the cingulate and superior frontal gyri on coronal slices. When the paracingulate sulcus was present, the paracingulate gyrus, which corresponds approximately to Brodmann area 32, was excluded from the cingulate gyrus measurement. In order to examine the influence of the paracingulate gyrus on the volumes of the cingulate gyrus, the numbers of cases with paracingulate sulci present were compared between groups. The presence of a paracingulate sulcus can be asymmetrical between cerebral hemispheres, and for this reason its presence or absence was examined in both hemispheres.

To assess inter-rater reliability, 2 raters (TA \& TK) blinded to diagnoses independently delineated the ROIs for 6 random cases. Intraclass correlation coefficients for right and left sides were as follows: 0.987 and 0.984 for the cognitive, 0.989 and 0.875 for the subgenual, and 0.996 and 0.995 for the affective subregions.

\section{Statistical Analysis}

Statistical analyses were performed using PASW software (SPSS Japan Inc., an IBM company). $T$-tests assessed group differences in demographics, clinical characteristics, and behavioral performance on the Stroop task. For ERP measurements, group differences were assessed using mixed model repeated measures ANOVA with diagnostic group as the between-subjects factor, and electrode position ( F3, Fz, F4, C3, Cz, C4) as the withinsubjects factor. The relative MRI volume ([absolute ROI volume/ICC] $\times 100)$ was used as the dependent variable for a mixed model repeated measures ANOVA, with diagnostic group as the between-subjects factor and ACC subregions (cognitive, affective, subgenual) and hemisphere as the within-subjects factors.

Pearson's correlations were performed in order to assess the relationship between the absolute volume of ROIs and ERN/CRN amplitudes. Since our primary prediction was the association between cognitive subregion volume and ERN in healthy subjects which might be disrupted in schizophrenia patients, we regarded $p<0.05$ as statistical significance and did not use correction for multiple comparisons. If the significant correlation was found in the healthy group, the specificity of the correlation to that group was assessed by using Fisher's $\mathrm{r}$ to $\mathrm{z}$ transformation.

To test whether medication and symptomatology could affect ERP results, we performed Pearson's correlational analysis between ERN or CRN amplitudes at 6 electrodes and chlorpromazine equivalent doses (Woods, 2003), and PANSS scores (positive, negative, general, or total). Additionally, ERN or CRN amplitudes at 6 electrodes were compared between DSM-IV paranoid type $(\mathrm{N}=9)$ and other types $(\mathrm{N}=9)$ by using independent t-tests. Uncorrected $p<0.05$ was regarded as statistically significant.

\section{Results ERP results}

The error rate was not significantly different between groups $(t=1.72, p=0.095)$. There was no main effect of group on ERN amplitude $(\mathrm{F}[1,34]=1.04, \mathrm{p}=0.32)$, or interaction between group and electrode $(F[1,34]=0.01, p=0.94)$. In contrast, schizophrenia patients showed significantly larger $\mathrm{CRN}$ amplitude than did healthy subjects $(\mathrm{F}[1,34]=6.66, \mathrm{p}=$ 
$0.014)$, without a significant interaction between group and electrode $(F[1,34]=0.34, p=$ $0.56)$.

\section{MRI results}

Groups did not differ in gray matter volumes in any subregion of the ACC (main effect of group: $\mathrm{F}[1,30]=0.74, \mathrm{p}=0.40$; group $\mathrm{X}$ subregion interaction: $\mathrm{F}[2,60]=0.79, \mathrm{p}=0.46$; group $\mathrm{X}$ hemisphere interaction: $\mathrm{F}[1,30]=2.44, \mathrm{p}=0.13$; group $\mathrm{X}$ subregion $\mathrm{X}$ hemisphere interaction: $F[2,60]=2.10, p=0.13$ ) (table 4). Using absolute volume as the dependent variable and ICC as the covariate did not change the statistical conclusions.

\section{Correlation between ERP and ACC gray matter volumes}

There were significant negative correlations between ERN amplitudes at electrodes F3 ( $\mathrm{R}=$ $-0.588, \mathrm{p}=0.027), \mathrm{Fz}(\mathrm{R}=-0.687, \mathrm{p}=0.007), \mathrm{F} 4(\mathrm{R}=-0.552, \mathrm{p}=0.041), \mathrm{C} 4(\mathrm{R}=-0.571$, $\mathrm{p}=0.033$ ) and the absolute volumes of the left cognitive subregion, only in healthy controls (Table 5). Fisher's $\mathrm{r}$ to $\mathrm{z}$ transformation indicated that these correlations were specific to the controls $(\mathrm{z}=2.08-2.65 ; \mathrm{p}=0.008-0.038)$. There was no significant correlation between CRN amplitudes and gray matter volumes for any subregion of the ACC in either group (data not shown).

\section{Test for possible confounding factors for ERP results}

The correlational analysis between chlorpromazine equivalent dose and ERN or CRN amplitudes at 6 electrodes in schizophrenia patients was not significant (uncorrected $\mathrm{p}$ > 0.06). For symptomatology, we compared ERN or CRN amplitudes at 6 electrodes between DSM-IV paranoid type $(\mathrm{N}=9)$ and other types $(\mathrm{N}=9)$, which was not significant (t-test, $\mathrm{p}>0.08)$. Also, the correlation between ERN or CRN amplitudes at 6 electrodes and PANSS scores (positive, negative, general, or total) was not significant ( $p>0.1$ )

\section{Discussion}

The current study sought to investigate neural structural correlates of neurophysiological indexes of self-monitoring, measured by ERN \& CRN in patients with schizophrenia and in healthy subjects. The 2 groups did not differ in ERN amplitude. In contrast, schizophrenia patients were found to have significantly larger CRN amplitudes than healthy subjects. Although the 2 groups did not significantly differ in gray matter volume of any ACC subregions, a significant negative correlation was found between ERN amplitudes at the frontocentral electrodes, and gray matter volume of the left cognitive regions, only in healthy controls. These results suggest a disruption of the normal relationship between structure and function of brain regions sub-serving self monitoring in patients with schizophrenia.

In our study, the 2 groups did not differ significantly in ERN amplitudes; this is in contrast to the findings of previous studies, which have almost exclusively found a significant attenuation of ERN amplitude in patients with schizophrenia (Alain et al., 2002; Bates et al., 2002; Bates et al., 2004; Kim et al., 2006; Kopp and Rist, 1999; Mathalon et al., 2002; Morris et al., 2008; Morris et al., 2006). Morris et al., (2006) reported that the ERN amplitude was reduced in patients with schizophrenia, particularly under conditions where the accuracy was emphasized. In the present study, however, both accuracy and speed were emphasized. This discrepancy in the focus of encouragement might have unexpectedly affected the results. In contrast, CRN amplitude was significantly enhanced in patients with schizophrenia, consistent with previous studies (Alain et al., 2002; Kim et al., 2006; Mathalon et al., 2002; Morris et al., 2006). 
Moreover, a significant negative correlation was found between ERN amplitudes at the frontocentral electrodes and gray matter volumes of the left cognitive regions, only in healthy controls. These correlations were specific to healthy controls, confirmed by the Fisher's $r$ to $z$ transformation. The finding of an ERN association with the cognitive subregion of the ACC is also compatible with the inferences from previous EEG/fMRI studies (Edwards et al., 2012; Herrmann et al., 2004; van Veen and Carter, 2002). Although speculative, a possible explanation for a lack of the function-structure coupling in the patient group may be that, whereas synaptic density and local neuronal circuit integrity both contribute to the amplitude of ERP, MRI gray matter volume preferentially indexes the former, and that these two neuronal components might be differentially affected in each individual with schizophrenia. A combination of MRI volumetry and diffusion tensor imaging may clarify the issue in future investigations.

We need to comment upon the methodological issues of the present study. First, we did not find any significant reduction of ERN amplitude, or ACC volume in schizophrenia patients, possibly due to an insufficient sample size. Second, our subjects were all chronic, male schizophrenia patients. Testing patients at different stages of illness, as well as female patients will be necessary to generalize any results to a larger population. Finally, assessment of anterior cingulum bundle connectivity by using diffusion tensor imaging may be a sensitive tool and provide further insights into the structure-function relationships of brain regions subserving self-monitoring in schizophrenia.

In conclusion, the present study suggests a disruption of function-structure coupling of brain regions subserving self monitoring in schizophrenia. Combining the assessment of electrophysiological and structural MRI indices is an informative research strategy for working toward a comprehensive understanding of the pathophysiology of psychiatric disorders, including schizophrenia.

\section{Acknowledgments}

The authors thank all the participants in this study. The authors also thank all the staff members at Clinical Neuroscience Division, Laboratory of Neuroscience, Department of Psychiatry, Boston VA Healthcare System, Brockton Division and Harvard Medical School who helped with this study.

\section{Role of funding source}

This study was supported by Dept. of Veterans Affairs Medical Research Awards (Schizophrenia Center, Merit Awards to Drs. McCarley and Shenton) and by grants K02 MH01110 and R01MH50747 (Dr. Shenton), R01MH40799 and R01 MH 052807 (Dr. McCarley). The funding sources had no further role in study design; in the collection, analysis and interpretation of data; in the writing report; and in the decision to submit the paper for publication.

\section{References}

Alain C, McNeely HE, He Y, Christensen BK, West R. Neurophysiological evidence of errormonitoring deficits in patients with schizophrenia. Cereb Cortex. 2002; 12(8):840-846. [PubMed: 12122032]

Bates AT, Kiehl KA, Laurens KR, Liddle PF. Error-related negativity and correct response negativity in schizophrenia. Clin Neurophysiol. 2002; 113(9):1454-1463. [PubMed: 12169328]

Bates AT, Liddle PF, Kiehl KA, Ngan ET. State dependent changes in error monitoring in schizophrenia. J Psychiatr Res. 2004; 38(3):347-356. [PubMed: 15003441]

Botvinick M, Nystrom LE, Fissell K, Carter CS, Cohen JD. Conflict monitoring versus selection-foraction in anterior cingulate cortex. Nature. 1999; 402(6758):179-181. [PubMed: 10647008]

Botvinick MM, Braver TS, Barch DM, Carter CS, Cohen JD. Conflict monitoring and cognitive control. Psychol Rev. 2001; 108(3):624-652. [PubMed: 11488380] 
Botvinick MM, Cohen JD, Carter CS. Conflict monitoring and anterior cingulate cortex: an update. Trends Cogn Sci. 2004; 8(12):539-546. [PubMed: 15556023]

Bush G, Frazier JA, Rauch SL, Seidman LJ, Whalen PJ, Jenike MA, Rosen BR, Biederman J. Anterior cingulate cortex dysfunction in attention-deficit/hyperactivity disorder revealed by fMRI and the Counting Stroop. Biol Psychiatry. 1999; 45(12):1542-1552. [PubMed: 10376114]

Bush G, Luu P, Posner MI. Cognitive and emotional influences in anterior cingulate cortex. Trends Cogn Sci. 2000; 4(6):215-222. [PubMed: 10827444]

Carter CS, Braver TS, Barch DM, Botvinick MM, Noll D, Cohen JD. Anterior cingulate cortex, error detection, and the online monitoring of performance. Science. 1998; 280(5364):747-749. [PubMed: 9563953]

Edwards BG, Calhoun VD, Kiehl KA. Joint ICA of ERP and fMRI during error-monitoring. Neuroimage. 2012; 59(2):1896-1903. [PubMed: 21930218]

Falkenstein M, Hohnsbein J, Hoormann J, Blanke L. Effects of crossmodal divided attention on late ERP components. II. Error processing in choice reaction tasks. Electroencephalogr Clin Neurophysiol. 1991; 78(6):447-455. [PubMed: 1712280]

Falkenstein M, Hoormann J, Christ S, Hohnsbein J. ERP components on reaction errors and their functional significance: a tutorial. Biol Psychol. 2000; 51(2-3):87-107. [PubMed: 10686361]

Ford JM. Schizophrenia: the broken P300 and beyond. Psychophysiology. 1999; 36(6):667-682. [PubMed: 10554581]

Gehring WJ, Goss B, Coles MGH, Meyer DE, Donchin E. A Neural System for Error-Detection and Compensation. Psychological Science. 1993; 4(6):385-390.

Herrmann MJ, Rommler J, Ehlis AC, Heidrich A, Fallgatter AJ. Source localization (LORETA) of the error-related-negativity (ERN/Ne) and positivity (Pe). Brain Res Cogn Brain Res. 2004; 20(2): 294-299. [PubMed: 15183400]

Holroyd CB, Dien J, Coles MG. Error-related scalp potentials elicited by hand and foot movements: evidence for an output-independent error-processing system in humans. Neurosci Lett. 1998; 242(2):65-68. [PubMed: 9533395]

Kiehl KA, Liddle PF, Hopfinger JB. Error processing and the rostral anterior cingulate: an eventrelated fMRI study. Psychophysiology. 2000; 37(2):216-223. [PubMed: 10731771]

Kim MS, Kang SS, Shin KS, Yoo SY, Kim YY, Kwon JS. Neuropsychological correlates of error negativity and positivity in schizophrenia patients. Psychiatry Clin Neurosci. 2006; 60(3):303311. [PubMed: 16732746]

Koo MS, Levitt JJ, Salisbury DF, Nakamura M, Shenton ME, McCarley RW. A cross-sectional and longitudinal magnetic resonance imaging study of cingulate gyrus gray matter volume abnormalities in first-episode schizophrenia and first-episode affective psychosis. Arch Gen Psychiatry. 2008; 65(7):746-760. [PubMed: 18606948]

Kopp B, Rist F. An event-related brain potential substrate of disturbed response monitoring in paranoid schizophrenic patients. J Abnorm Psychol. 1999; 108(2):337-346. [PubMed: 10369044]

Laurens KR, Ngan ET, Bates AT, Kiehl KA, Liddle PF. Rostral anterior cingulate cortex dysfunction during error processing in schizophrenia. Brain. 2003; 126(Pt 3):610-622. [PubMed: 12566282]

Mathalon DH, Fedor M, Faustman WO, Gray M, Askari N, Ford JM. Response-monitoring dysfunction in schizophrenia: an event-related brain potential study. J Abnorm Psychol. 2002; 111(1):22-41. [PubMed: 11866176]

Miltner WH, Lemke U, Weiss T, Holroyd C, Scheffers MK, Coles MG. Implementation of errorprocessing in the human anterior cingulate cortex: a source analysis of the magnetic equivalent of the error-related negativity. Biol Psychol. 2003; 64(1-2):157-166. [PubMed: 14602360]

Morris SE, Heerey EA, Gold JM, Holroyd CB. Learning-related changes in brain activity following errors and performance feedback in schizophrenia. Schizophr Res. 2008; 99(1-3):274-285. [PubMed: 17889510]

Morris SE, Yee CM, Nuechterlein KH. Electrophysiological analysis of error monitoring in schizophrenia. J Abnorm Psychol. 2006; 115(2):239-250. [PubMed: 16737389]

Olvet DM, Hajcak G. The error-related negativity (ERN) and psychopathology: toward an endophenotype. Clin Psychol Rev. 2008; 28(8):1343-1354. [PubMed: 18694617] 
Stemmer B, Segalowitz SJ, Witzke W, Schonle PW. Error detection in patients with lesions to the medial prefrontal cortex: an ERP study. Neuropsychologia. 2004; 42(1):118-130. [PubMed: 14615082]

van Veen V, Carter CS. The anterior cingulate as a conflict monitor: fMRI and ERP studies. Physiol Behav. 2002; 77(4-5):477-482. [PubMed: 12526986]

van Veen V, Cohen JD, Botvinick MM, Stenger VA, Carter CS. Anterior cingulate cortex, conflict monitoring, and levels of processing. Neuroimage. 2001; 14(6):1302-1308. [PubMed: 11707086]

Vidal F, Hasbroucq T, Grapperon J, Bonnet M. Is the 'error negativity' specific to errors? Biol Psychol. 2000; 51(2-3):109-128. [PubMed: 10686362]

Westlye LT, Walhovd KB, Bjornerud A, Due-Tonnessen P, Fjell AM. Error-related negativity is mediated by fractional anisotropy in the posterior cingulate gyrus--a study combining diffusion tensor imaging and electrophysiology in healthy adults. Cereb Cortex. 2009; 19(2):293-304. [PubMed: 18502729]

Whalen PJ, Bush G, McNally RJ, Wilhelm S, McInerney SC, Jenike MA, Rauch SL. The emotional counting Stroop paradigm: a functional magnetic resonance imaging probe of the anterior cingulate affective division. Biol Psychiatry. 1998; 44(12):1219-1228. [PubMed: 9861465]

Wible CG, Shenton ME, Hokama H, Kikinis R, Jolesz FA, Metcalf D, McCarley RW. Prefrontal cortex and schizophrenia. A quantitative magnetic resonance imaging study. Arch Gen Psychiatry. 1995; 52(4):279-288. [PubMed: 7702444]

Woods SW. Chlorpromazine equivalent doses for the newer atypical antipsychotics. J Clin Psychiatry. 2003; 64(6):663-667. [PubMed: 12823080] 


\section{Healthy Subjects $(\mathrm{N}=18)$}
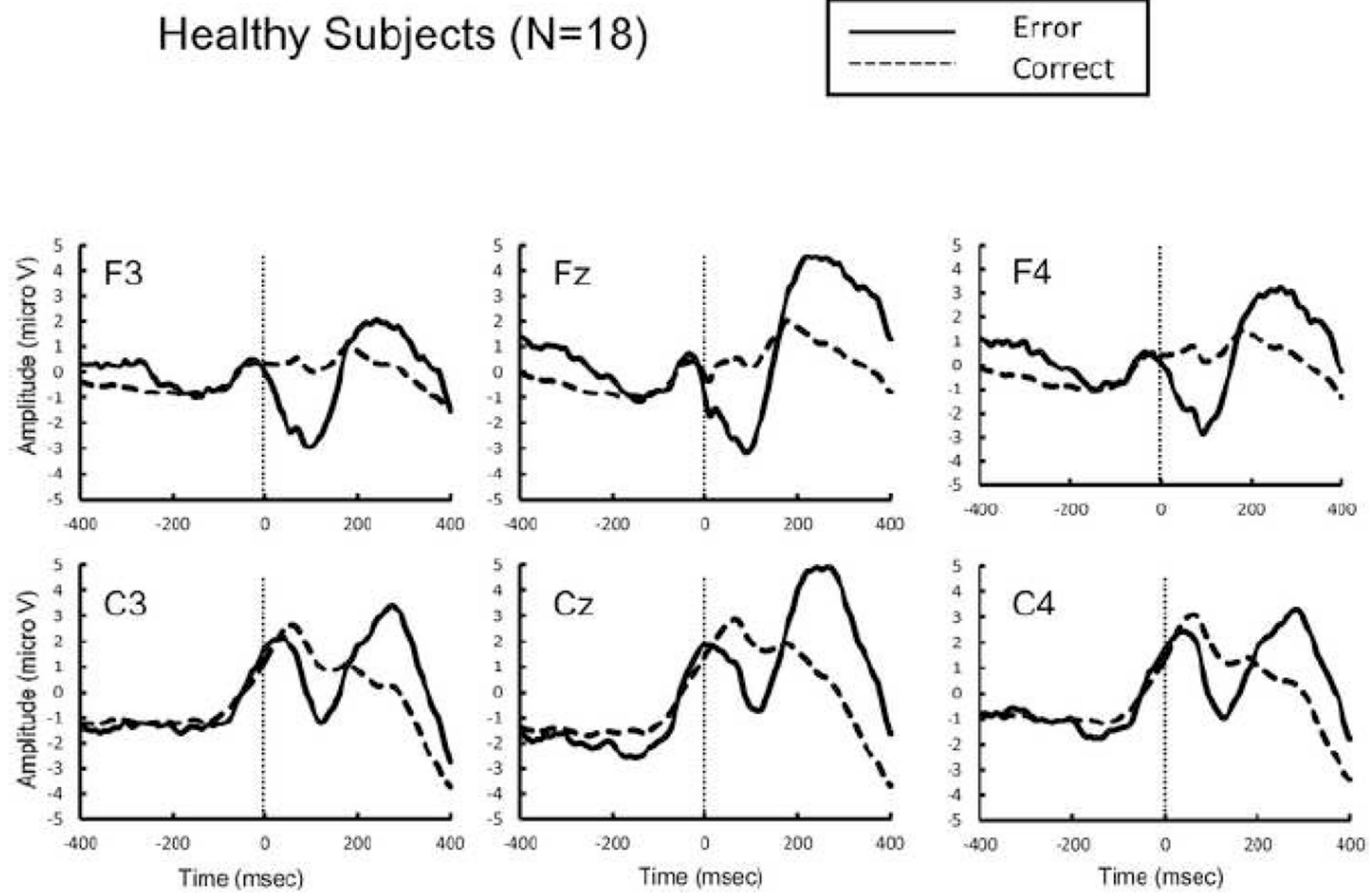

Figure 1.

Response-locked grand average event related potential (ERP) waveforms from healthy subjects following errors (thick lines) and correct responses (dotted lines). 


\section{Patients with Schizophrenia $(\mathrm{N}=18) \mid \begin{array}{ll}- & \text { Error } \\ -\cdots-\cdots & \text { Correct }\end{array}$}
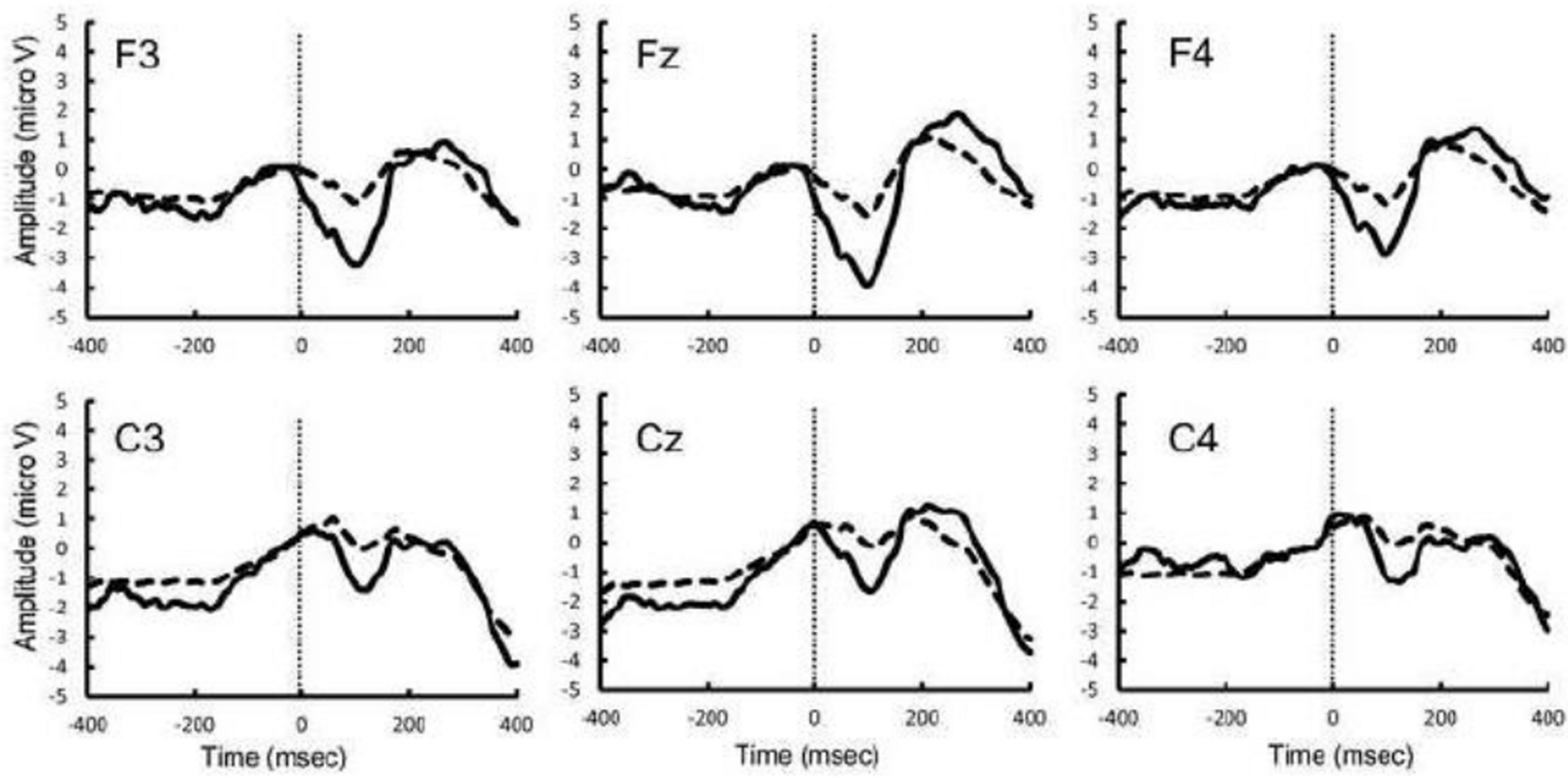

Figure 2.

Response-locked grand average event related potential (ERP) waveforms from patients with schizophrenia following errors (thick lines) and correct responses (dotted lines). 
Errors
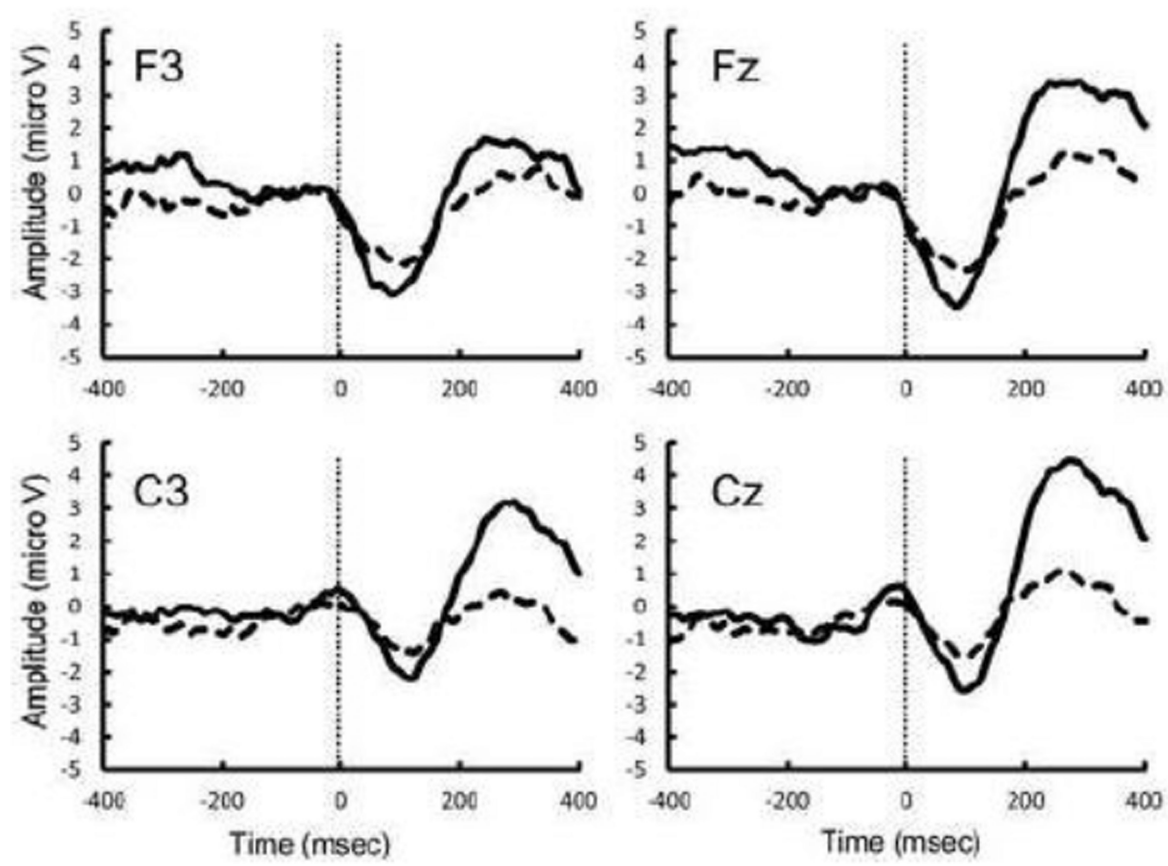

Healthy Subjects ( $N=18$ )

Patients with Schizophrenia ( $N=18)$

Figure 3.

Response-locked grand average event related potential (ERP) waveforms from healthy subjects (thick lines) and patients with schizophrenia (dotted lines) following errors. 


\section{Correct Responses}
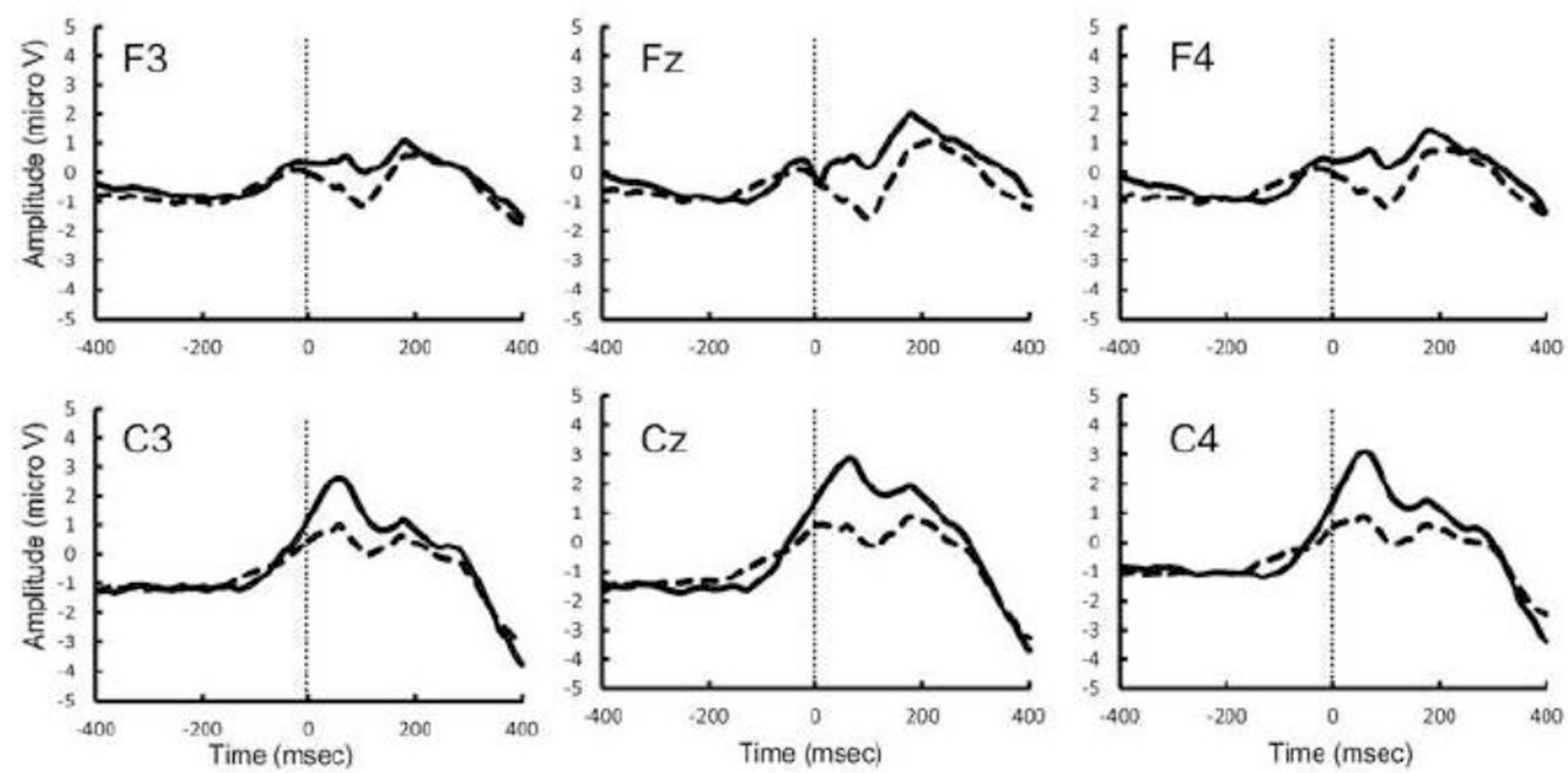

Figure 4.

Response-locked grand average event related potential (ERP) waveforms from healthy subjects (thick lines) and patients with schizophrenia (dotted lines) following correct responses. 


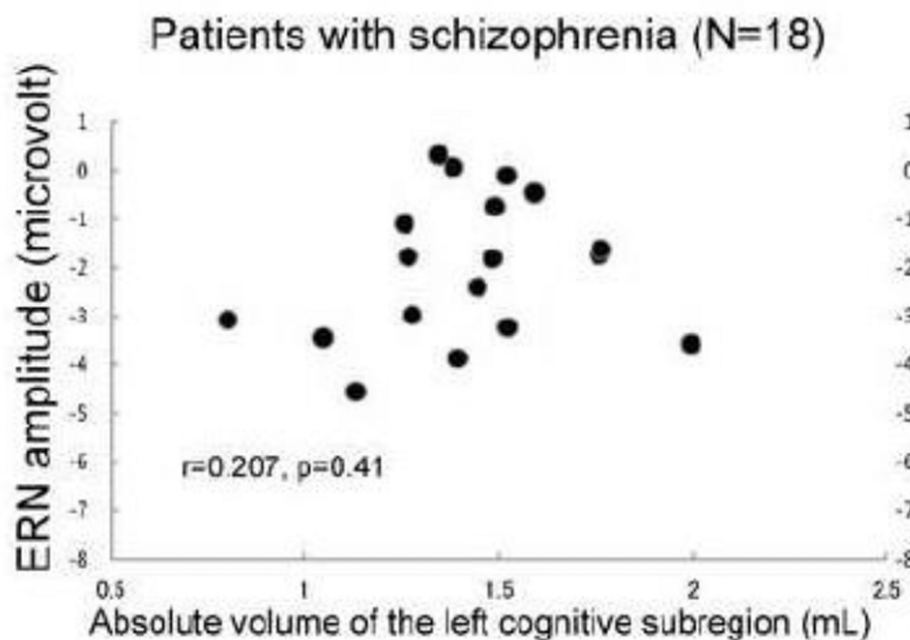

Patients with schizophrenia ( $\mathrm{N}=18$ )

Healthy Subjects $(\mathrm{N}=14)$

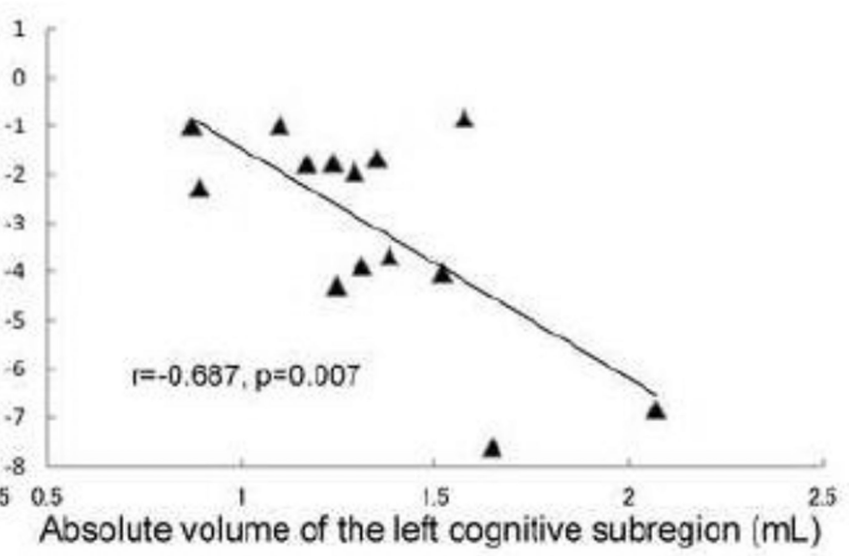

Figure 5.

The scatterplot shows the relationship between ERN amplitude and the absolute gray matter volume of the left cognitive subregion of anterior cingulate gyrus. 


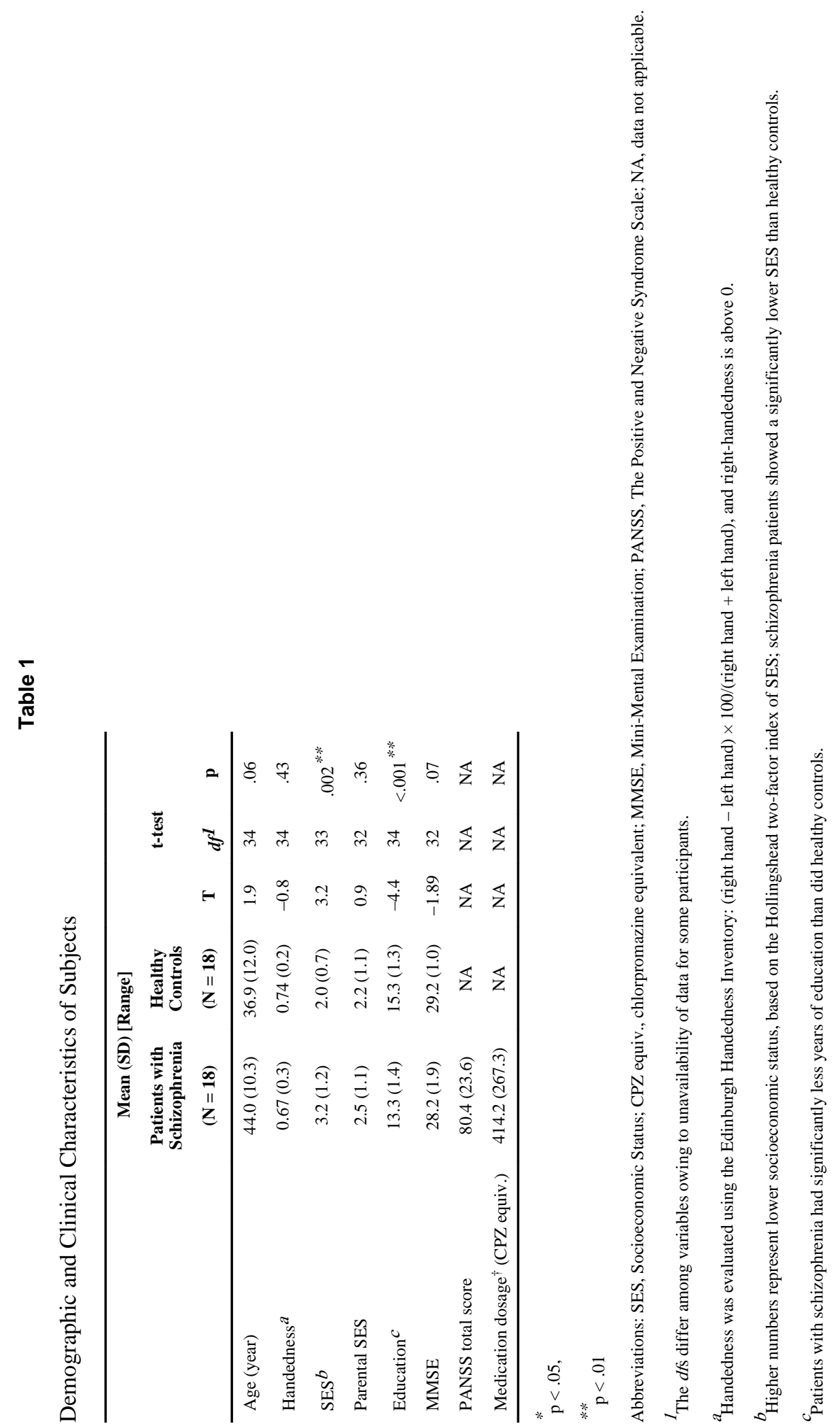




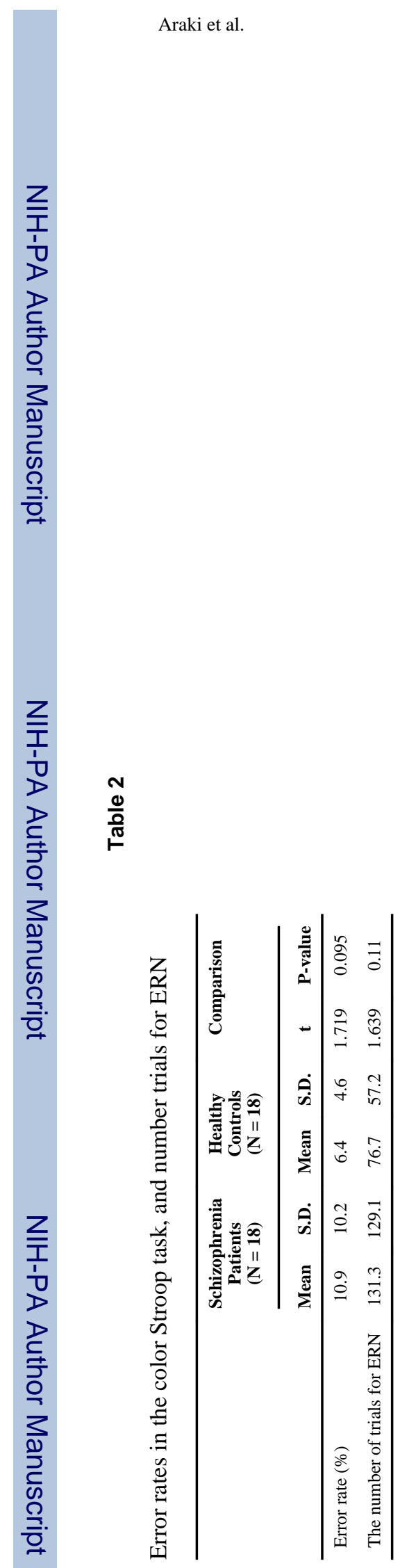

Page 16

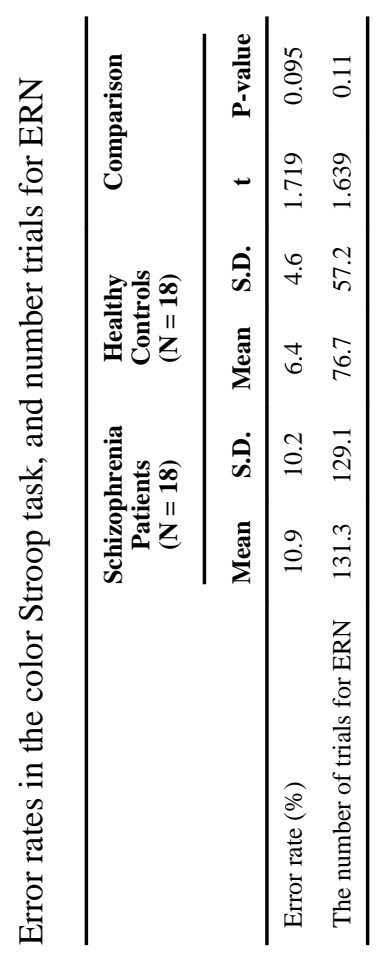

Schizophr Res. Author manuscript; available in PMC 2014 May 01. 


\section{Table 3}

Event-related potential amplitudes

\begin{tabular}{lcccc}
\hline & $\begin{array}{c}\text { Schizophrenia } \\
\text { Patients (N = 18) }\end{array}$ & \multicolumn{2}{c}{$\begin{array}{c}\text { Healthy } \\
\text { Controls (N = 18) }\end{array}$} \\
\cline { 2 - 5 } & Mean $^{*}$ & S.D.* & Mean & S.D. \\
\hline ERN, F3 & -1.84 & 1.17 & -2.51 & 2.73 \\
ERN, C3 & -0.98 & 1.24 & -1.39 & 1.75 \\
ERN, Fz & -2.00 & 1.47 & -2.58 & 2.52 \\
ERN, Cz & -1.12 & 1.59 & -1.8 & 2.73 \\
ERN, F4 & -1.34 & 1.31 & -2.36 & 3.21 \\
ERN, C4 & -0.78 & 1.4 & -1.46 & 3.27 \\
CRN, F3 & -0.63 & 1.35 & 0.29 & 1.94 \\
CRN, C3 & 0.60 & 1.48 & 1.76 & 1.73 \\
CRN, Fz & -0.94 & 1.39 & 0.54 & 1.85 \\
CRN, Cz & 0.39 & 1.78 & 2.18 & 2.18 \\
CRN, F4 & -0.68 & 1.41 & 0.5 & 1.96 \\
CRN, C4 & 0.51 & 1.35 & 2.17 & 1.63 \\
\hline
\end{tabular}

Micro-volts 
